\title{
ASSESSMENT OF DESIGN REQUIREMENTS AGAINST PROGRESSIVE COLLAPSE IN UFC 4-023-03: NUMERICAL SIMULATION
}

\author{
H.H. Li ${ }^{1,2,{ }^{*}}$, B.Y. Zhang ${ }^{1,2}$ and X.H. Cai ${ }^{3}$ \\ ${ }^{1}$ Key Lab of Structures Dynamic Behavior and Control of the Ministry of Education, \\ Harbin Institute of Technology, Harbin, 150090, China \\ ${ }^{2}$ Key Lab of Smart Prevention and Mitigation of Civil Engineering Disasters of \\ the Ministry of Industry and Information Technology, \\ Harbin Institute of Technology, Harbin, 150090, China \\ ${ }^{3}$ Architectural Design and Research Institute of HIT \\ *(Corresponding author: Email: lihonghao@hit.edu.cn)
}

Received: 18 November 2016; Revised: 15 July 2017; Accepted: 19 September 2017

\begin{abstract}
Unified Facilities Criteria (UFC 4-023-03): Design of Buildings to Resist Progressive Collapse published by the Department of Defense is one of the few design provisions that have been used around the US which provide design requirements on the basis of conventional design philosophy to the designers and the owners of the buildings against progressive collapse. These requirements are evaluated using numerical models which have been shown to be able to reasonably capture the behaviors of the buildings under column loss scenarios. A large number of case studies are conducted using validated three-dimensional macro-based models for four prototype buildings with different size, different height, different seismic detailing and different structural layouts. The simulation results show that the tie force method (TFM) is effective in protecting steel framed buildings against progressive collapse and can significantly reduce overall deformations of the structures after sudden loss of a column. However, the method for calculating the dynamic increase factor (DIF) proposed in the document is deemed problematic and thus a new energy-based approach is proposed to assess the peak dynamic displacement (PDD). The proposed method is shown to be accurate and reasonably conservative.
\end{abstract}

Keywords: 3-D macro-model, numerical simulation, UFC 4-023-03, tie force method, dynamic increase factor, peak dynamic displacement, energy-based method

DOI: $10.18057 /$ IJASC.2018.14.4.1

\section{INTRODUCTION}

Progressive collapse has become a popular research topic in the field of structural engineering since the partial collapse of Ronan Pointe Tower in England in 1968. Currently, many ongoing studies related to progressive collapse are being conducted by federal agencies, research institute and universities. The ultimate goal of progressive collapse studies is to develop design and retrofit strategies so that the structures are not vulnerable to progressive collapse when subjected to abnormal loading conditions.

Currently, ASCE 7-10 [1] is the only mainstream standard that addresses the issue of collapse in some detail in the United States. It specifies two design alternatives: 1) a direct design method, which either considers explicit conditions for analysis when specific members are no longer capable of supporting load (Alternate Path Method), or ensures sufficient local strength to resist possible failure induced by accidents or misuse; 2) indirect design method, which includes implicit considerations that would enhance resistance to collapse through provision of minimum levels of strength, continuity and ductility. The provisions to prevent collapse in the UFC 4-023-03 (DoD [2]) and General Services Administration progressive guidelines (GSA [3]) were based on a similar philosophy to that in ASCE 7-10 [1], albeit with more details. The GSA progressive guidelines 
(GSA [3]) and UFC 4-023-03 (DoD [2]), in particular, specify the Alternate Path Method (APM) as one of several alternatives, and promote linear and nonlinear analysis techniques to check structural members in the alternate path structure. Both documents are geared towards blast hazards and their primary intent is to protect a building that has lost critical structural members to a blast. The design approaches in UFC 4-023-03 [2] vary according to the building occupancy. Although much research has been done to develop these provisions, their conservatism and effectiveness in protecting buildings from progressive collapse under column-loss scenarios still needs to be evaluated through experimentations and simulations. The UFC 4-023-03 [2], in particular, need refinement because they were modeled after seismic performance based design guidelines and have yet to be fully adapted for gravity-induce collapse situations.

In the UFC 4-023-03 [2], one of the techniques permitted for designing against collapse is the Tie Force Method (TFM). This is an indirect technique, permitted under certain occupancy conditions, in which structural robustness is assured by promoting structural continuity, ductility, and structural redundancy. Robustness is achieved by specifying the minimum amount of tensile forces and their locations that must be provided to 'tie' the structure together. The TFM procedures traces its origins to British engineers involved in the 1968 Ronan Point incident and is one of the earliest design strategies against progressive collapse. The UK Building Establishment (BRE) conducted quarter-scale testing to determine its effectiveness as early as 1970s (Moore [4]). A number of studies have been conducted in the past decade to evaluate the adequacy of TFM for progressive collapse. Abruzzo et al. [5] investigated the behavior of a reinforced concrete commercial building designed according to older version of UFC 4-203-03 [2] under column loss scenarios and claimed that the TFM specified in UFC 4-203-03 (DoD [6]) was inadequate to prevent progressive collapse. Li et al. [7] evaluated the effectiveness of TFM specified in the British Standard in resisting progressive collapse of reinforced concrete frame structures and proposed an improved TFM. Tohidi et al. [8] conducted similar studies for precast concrete cross wall structures. Main [9] showed the effectiveness of tie forces requirements specified by the latest version of UFC 4-023-03 (DoD [2]) in preventing progressive collapse of a 2 by 2 bay composite floor system using a macro-based finite element model. It was found that the requirements might become unconservative when the system carried large load and a new equation was proposed for the calculation of tie forces for collapse prevention. One common shortcoming of the above studies is that none of the models used in these studies were able to represent a full 3-D multi-story building.

Another concept promoted by the provisions is the dynamic increase factor (DIF), which is used to predict the dynamic behavior of a building using static analysis by simply magnifying its corresponding static loads by DIF. In older versions UFC 4-023-03 (DoD [6]) and GSA [10], DIF was taken as 2.0, based on the behavior of elastic systems. This number has been proved to be too conservative by several researchers (Ruth et al. [11], Foley et al. [12], Khandelwal and El-Tawil [13]), primarily because system response is inelastic and not elastic. A series of experimental and numerical studies have been conducted to evaluate the DIF recently, such as Liu [14], Yu et al. [15], Ali et al. [16], Liu et al. [17] and Liu et al. [18]. It was demonstrated in Liu et al. [18] that method for the calculation of DIF provided by UFC 4-023-03 (DoD [2]) was unsafe under large deformation conditions when catenary action played the key role in resisting progressive collapse. The effects of slabs were neglected in all of these studies. However, the experimental tests conducted by Qian and Li [19] showed that the slab system played a significant role in determining the dynamic performance of RC frame structure subjected to sudden loss of a column. Thus, it is necessary to consider the effects of the floor slabs when determining the DIF for a certain structural system. 
In summary, both sets of provisions (TFM and DIF) in UFC 4-023-03 (DoD [2]) have not yet to be thoroughly evaluated using well calibrated full 3-D nonlinear models including floor slab systems. This study sheds light on addressing the gaps in knowledge identified above. In particular, nonlinear dynamic and nonlinear static analysis are performed to assess the effectiveness of TFM in protecting steel framed structures against progressive collapse and the accuracy of the equations for calculating the DIF provided by UFC 4-023-03 (DoD [2]) using three-dimensional macro-based models. Numerous cases studies are conducted for four prototype buildings with different size, height, seismic detailing and structural layouts. A novel energy-based approach, which could replace the dynamic impact factor when assessing peak dynamic displacement (PDD) using static analysis, is proposed and its accuracy is evaluated. The applicability of the proposed method is also discussed in this study.

\section{PROTOTYPE STRUCTURES, MODELING APPROACHES, SIMULATION STEUP AND NAMING SCHEME}

\subsection{Prototype Structures}

In order to ensure that the analytical results are generally applicable, four prototype steel framed buildings are selected for case studies. All of the 4 buildings utilize moment resisting frames as the primary lateral load resisting system and simple shear connections are used in the gravity system. The structural layouts of the four buildings are outlined in Figure 1. The building shown in Figure 1(a) is a ten-story office building designed by the National Institute of Standard and Technology (NIST) for the purpose of investigating the collapse behavior of the building subjected to sudden column loss and it is designated as NIST-10. This building is designed for Seattle, WA, and categorized as Seismic Design Category D. Design details can be found in Liang et al. [20], Khandelwal et al. [21], and Alashker et al. [22]. The other three buildings are actually a set of buildings selected from the SAC model buildings in FEMA-335C (FEMA [23]), which were designed for the purpose of investigating the seismic performance of moment-resisting frame structures. They were designed for the Boston area using pre-Northridge connection configurations. This set of buildings consists of a three-story, a nine-story, and a twenty-story building and are designated as SAC-3, SAC-9, and SAC-20, respectively (Figure 1(b), Figure 1(c), and Figure 1(d)). These configurations are chosen because they represent typical steel framed office buildings designed for low-seismic risk, to contrast with NIST-10, which represents common steel framed office buildings designed for high seismic risk. Design details of these three buildings can be found in Foley et al. [24] and Hoffman [25]. Standard beam-to-column welded connections (WUF) are used in these buildings, unlike the NIST building, in which reduced beam sections (RBS) were used in the moment frames. The floor composite floor of the NIST-10 building is comprised of a RC slab of thickness $82.5 \mathrm{~mm}$ sitting on a steel deck with $76 \mathrm{~mm}$ depth and connected to the underlying steel beams via shear studs. Steel reinforcement mesh in the RC slab is $0.06 \mathrm{~mm} 2 / \mathrm{mm}$ in both directions. The composite floor in the three SAC buildings are identical. The composite floor is comprised of a $76 \mathrm{~mm}$ thick RC slab sitting on a $51 \mathrm{~mm}$ tall 19 gauge steel deck. The composite floor is connected to the underlying steel beams using shear studs and $6 \times 6-\mathrm{W} 1.4 \times 1.4$ welded wire mesh reinforcement is used in the RC slab. Thus, the four prototype structures can cover different structural layouts, types of connections, and heights.

\subsection{Modeling Approaches}

Three-dimensional macro-based models are used to represent the prototype buildings. The general modeling approach adopted in this study is to model all primary structural elements in the system, including the beams, columns, slab systems, and the connections between them. Since the focus of 
the study is on nonlinear response, each element's representation permits inelastic response to occur including fracture and separation, where appropriate. To enable realistic simulations of collapse, interpenetration between the various components of each model is prohibited. Therefore, falling components can introduce impact forces on the components with which they come in contact. The simulations are conducted with a single damping parameter that resulted in mass proportional damping ratios that ranged from $2 \%$ to $5 \%$, depending upon the initial dynamic properties of the simulation in question. The simulations are carried out using the explicit finite element code LS-DYNA (Hallquist [26]).

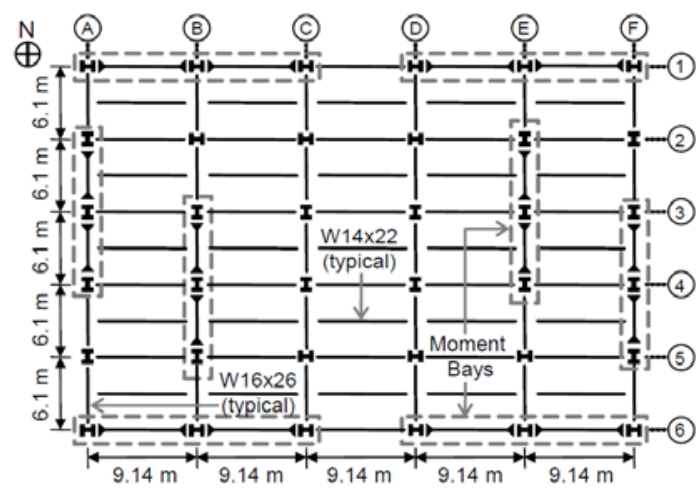

(a) NIST-10

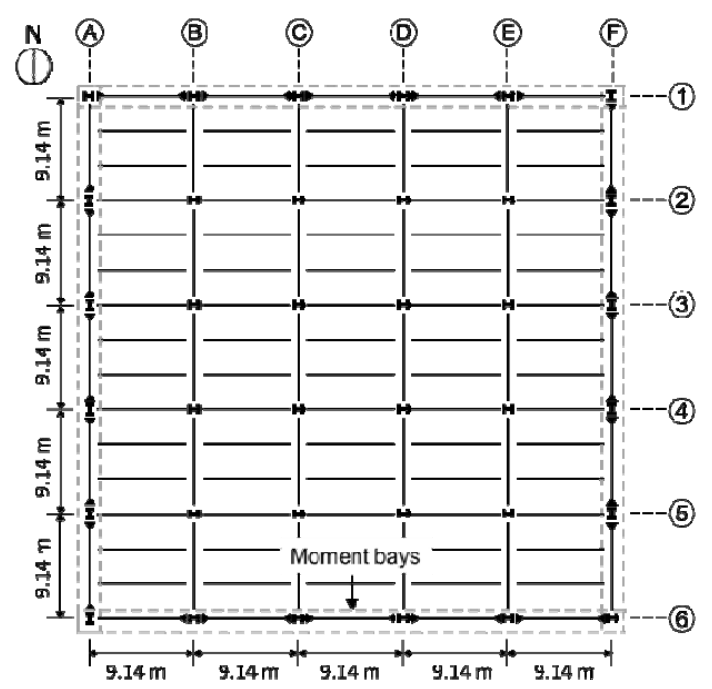

(c) SAC-9

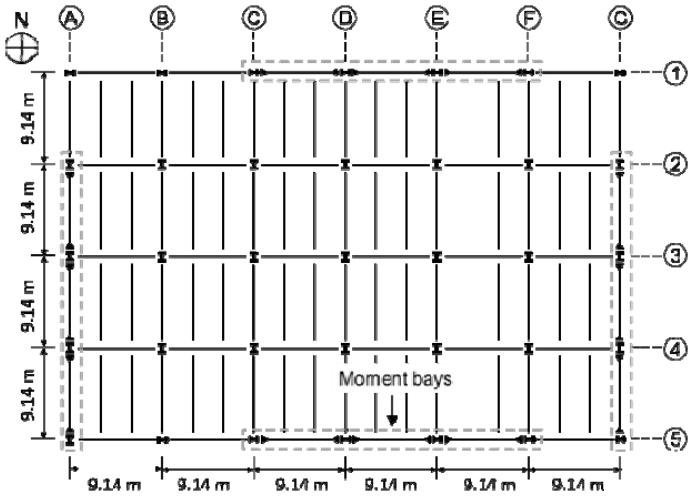

(b) SAC-3

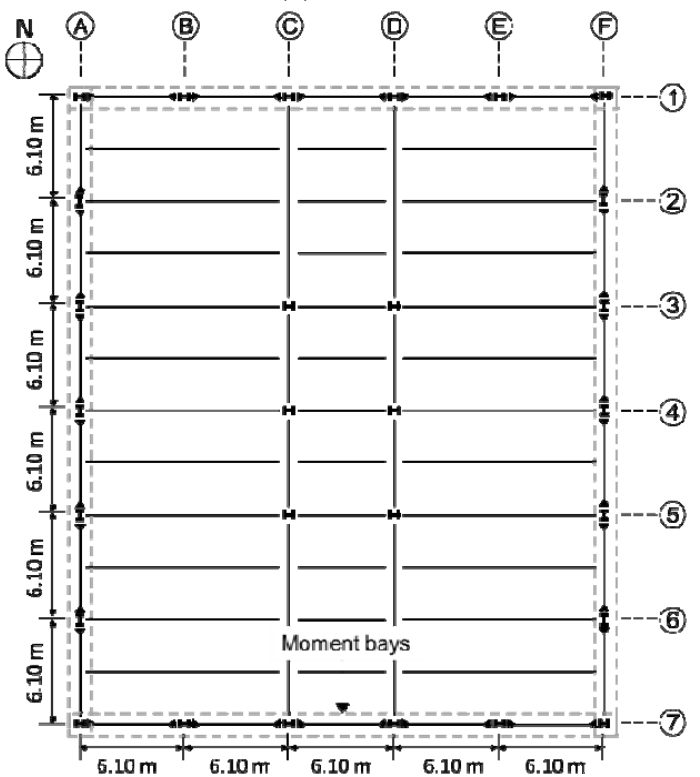

(d) SAC-20

Figure 1. Structural Layouts of the Prototype Buildings

In these models, beams and columns are represented using a Hughes-Liu beam-column element formulation. The shear tab is modeled by a single beam element, which has integration points that correspond to the location of individual bolts, and a binding spring to represent contact between the beam and column flanges, as specified in Khandelwal and El-Tawil [27]. The binding spring had no tensile capacity and its compressive capacity and subsequent inelastic behavior are calibrated from detailed studies of the connection region. Unlike the macro model discussed in Khandelwal and El-Tawil [27], which represents the panel zone, the models used herein do not include such a detail to cut down on computational cost. The decision to do so was motivated by extensive preliminary studies that showed that the panel zone does not contribute significantly to the collapse response of the prototype building. A reduced model of the composite floor system is employed in this study. 
The RC slab is modeled using fully integrated four-node, isotropic shell elements. A J2 plasticity model that can accommodate different tensile and compressive yield responses is used to model the $\mathrm{RC}$ slab. Since the steel deck can only develop resistance along the directions of the flutes, its effect is represented using bars element attached directly to the shell elements by sharing their nodes. The comparison between the responses of a composite floor system modeled using the modeling approach described previously (Alashker et al. [22]) and a detailed model (Sadek et al. [28]) showed that the proposed model was capable of representing the behavior of the composite floor system under column loss scenarios reasonably. The floor slab and the underlying steel beams are connected through rigid links. The links are intended to model the physical separation that exists between the center plane of the slab and that of the top beam flange, but cannot capture the inelastic behavior of the shear studs. The model for NIST-10 is designated as M2 in Alashker et al. [22] and $\mathrm{Li}$ and El-Tawil [29] but is designated as M2-NIST-10 under the naming scheme of this study. The models for the SAC buildings are designated as M2-SAC-3, M2-SAC-9, and M2-SAC-20, respectively. The 3-D overviews of the four models are shown in Figure 2.

Model M2-NIST-10 was extensively validated in previous studies (Alashker et al. [22] and Li and El-Tawil [29]) through comparisons to disparate experimental data and the results of more refined models and it was demonstrated that the 3-D macro-based model is accurate and reliable enough to represent the behavior of the structure under column loss scenarios. The details of modeling approaches and validation studies can be found in Alashker et al. [22] and Li and El-Tawil [29]. Since the same modeling approaches are employed for the other three buildings, confidence can be established in M2-SAC-3, M2-SAC-9, and M2-SAC-20.

\subsection{Simulation Setup}

All the models are exercised within an AMP setting and both nonlinear dynamic and nonlinear static procedures are implemented in this study. In the nonlinear dynamic analyses, the gravity loads are applied gradually within 5.0 seconds, followed by a wait period of 2.5 seconds in order to eliminate dynamic effects. After that, a column is removed by deleting it instantaneously. In the nonlinear static analyses, the column of interest is firstly removed, then the gravity loads are applied statically.

\subsection{Naming Scheme}

To facilitate the following discussion, the columns are designated as C-P-N-X. In this notation, $\mathrm{C}$ is the structural element type, i.e. columns. $\mathrm{P}$ is the position of the structural number described by the closest column lines in Figure 1. $\mathrm{N}$ is the story number and $\mathrm{X}$ is the notation of the building that the column belongs to, in which N10 represents the NIST-10 building, S3 represents the SAC-3 building, S9 represents the SAC-9 building, and S20 represents the SAC-20 building. For example, C-D6-5-N10 represents the column at the junction of column lines D and 6 in the 5th floor of the building NIST-10. C-C4-1-S9 represents the column junction of column lines $\mathrm{C}$ and 4 in the first floor of the building SAC-9.

\section{EVALUATION OF TIE FORCE METHOD}

Tie force method (TFM) is an indirect design approach advocated by UFC 4-023-03 (DoD [2]) with the objective of "enhancing continuity, ductility, and development of alternate load paths". Two types of ties are required: horizontal ties and vertical ties, and both can be proportioned using methods provided in UFC 4-023-03 (DoD [2]). There are three types of horizontal ties that must be provided by the structural system: longitudinal, transverse, and peripheral. For framed structures, 
the floor and roof system should carry the required longitudinal, transverse, and peripheral ties if the beams, girders and spandrels cannot be proven capable of carrying the tie force while undergoing a 0.20 -rad rotation.

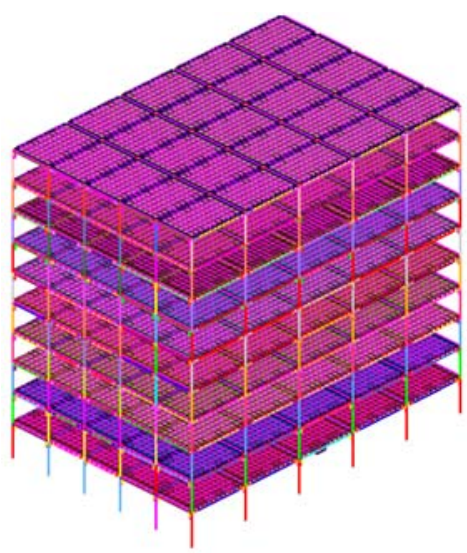

(a) Model M2-NIST-10

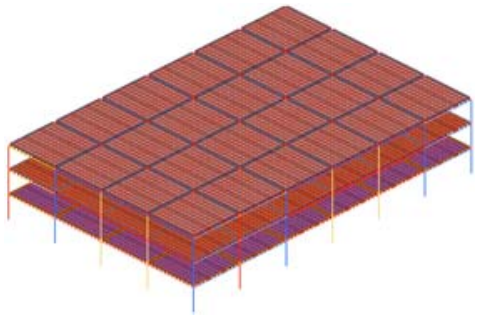

(b) Model M2-SAC-3

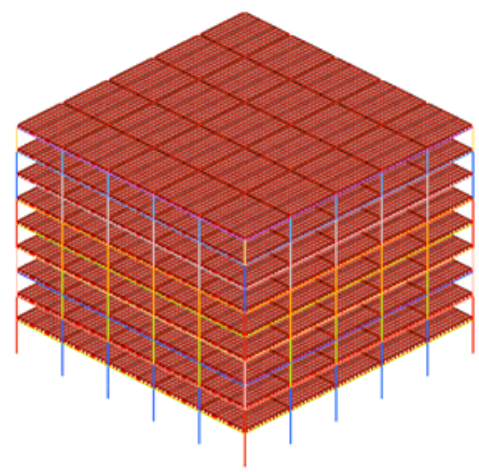

(c) Model M2-SAC-9

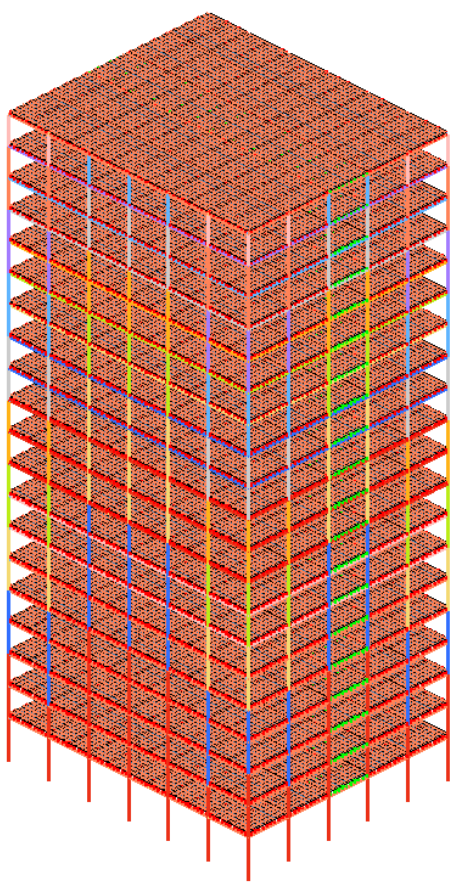

(d) Model M2-SAC-20

Figure 2. 3-D Overviews of the Models that are used in this Study

According to UFC 4-023-03 (DoD [2]), The required tie strength $F_{l}$ in the longitudinal or transverse direction is:

$F_{i}=3 W_{F} L_{1}$

Where

$W_{F}=1.2 D+0.5 L$ is the uniform floor load;

$L_{1}=$ greater of the distances between the centers of the columns, frames, or walls supporting any two adjacent floor spaces in the direction under consideration.

The rationality of the above equation can be shown through a simple analysis. The deformation of a frame structure subjected to loss of an interior column is shown in Figure 3(a). It is assumed that the maximum vertical displacement above the removed column reaches $0.2 \mathrm{~L}$ given that the rotation limitation of beams is $0.20 \mathrm{rad}$ according to UFC 4-023-03 (DoD [2]), where L is the span length of the frame structure. Under such deformation, plastic hinges should be formed at the ends of the beams and therefore the highlighted double span beam in Figure 3(a) can be modeled in the manner shown in Figure 3(b). By applying the equilibrium condition, the tie forces $F_{T}$ can be calculated:

$$
F_{T}=\frac{w L^{2}}{2} / 0.2 L=2.5 w L
$$

The coefficient of 2.5 in Eq. 2 is rounded up to 3.0 in the UFC 4-023-03 (DoD [2]). 
The required peripheral ties, which are used for providing "adequate development or anchors at corners" (DoD [2]) and have to be placed within $1.0 \mathrm{~m}$ of the edge of a floor or roof, can be calculated as:

$F_{P}=6 W_{F} L_{1} L_{P}+3 W_{C}$

Where

$L_{\mathrm{p}}=1.0 \mathrm{~m}$;

$L_{1}=$ The greater of the distances between the centers of the columns, frames or walls, at the perimeter of the building in the direction under consideration;

$W_{\mathrm{c}}=1.2 \times$ Dead load of cladding over the length of $L_{1}$.

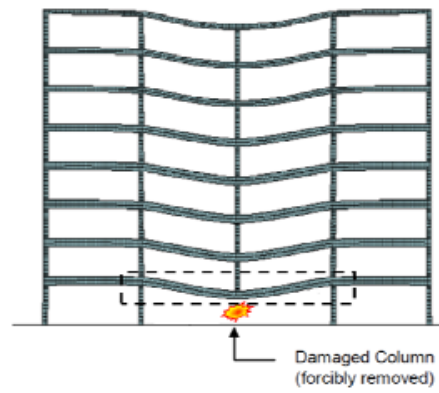

(a) Deformation of a frame structure subjected to loss of an interior column

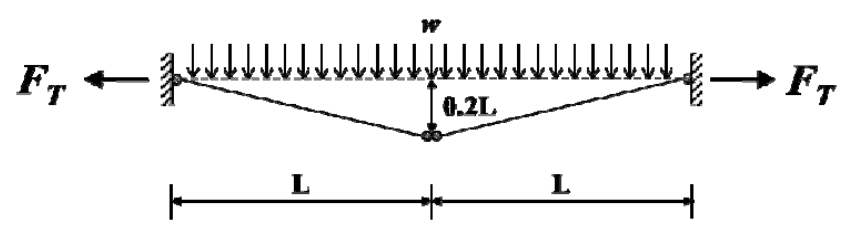

(b) Analytical model for calculating the tie forces

Figure 3. Simple Analysis of the Tie Force Method Equation

Similar with the longitudinal and transverse ties, the peripheral ties have to be carried by the floor and roof system unless the beams, girders, or spandrels could be shown to be capable of carrying the peripheral tie force while undergoing a $0.20-\mathrm{rad}$ rotation.

According to ASCE 41-06: Seismic Rehabilitation of Existing Buildings (ASCE [30]), the plastic rotation angles for RBS connections and WUF connections cannot reach 0.20 . Khandelwal and El-Tawil [27] also illustrated that the beam end rotations for these two types of connections cannot fulfill this requirement. Thus, the horizontal tie forces have to be carried by the slab systems. However, the welded wire reinforcement and the steel deck of the four prototype buildings cannot provide adequate horizontal ties required by Eq. 1 and Eq. 3. In order to develop the required tie forces in the slabs, reinforcing bars have to be added to the slabs in all of the four prototype buildings. The reinforcing bars used herein are ASTM grade 60 reinforcing steel with a minimum specified yield strength of $414 \mathrm{MPa}$. It is assumed that all of the required tie forces are carried by the reinforcing bars and no contribution from the steel deck and welded wire reinforcement is considered. The variation of models M2-X are developed. The model name is appended with ATF to signify that adequate tie forces are provided, e.g. M2-NIST-10-ATF, M2-SAC-3-ATF, M2-SAC-9-ATF, and M2-SAC-20-ATF. The variant models M2-X-ATF are identical to M2-X except the revised slab reinforcements. The reinforcing bars in the variant models are modeled using truss elements which are directly attached to the slabs. Similarly with the steel deck, these reinforcing bars is also assumed to be placed at the concrete centerline. This assumption is reasonable since the flexural behavior of the floor system is not as important as the tensile strength for collapse mitigation. The material property of the rebar is represented using a plastic-kinematic model and an elastic-perfectly plastic relationship is used to model the stress-stain response of the rebar. The elongation at fracture of the rebar used is based on Table 3-4 in Wight and MacGregor [31] and is listed in Table 1. 
Table 1. Fracture Elongation of Rebar

\begin{tabular}{cc}
\hline Reinforcement type & Fracture elongation (\%) \\
\hline$\# 4$ & 9 \\
$\# 7$ & 8 \\
$\# 8$ & 8 \\
$\# 9$ & 7 \\
$\# 10$ & 7 \\
$\# 11$ & 7 \\
\hline
\end{tabular}

In order to investigate the role of the additional reinforcements in resisting progressive collapse, nonlinear dynamic analyses were performed using the original models (M2-X) and the models with adequate tie forces (M2-X-ATF) under various column loss scenarios. The responses (permanent deformation) between the models M2-X and M2-X-ATF subjected to similar collapse initiating events are compared. In all of the four prototype buildings, every possible single column loss case is considered in this study considering the symmetry of the structural framing plan.

\subsection{NIST-10}

Nine first floor column loss cases were investigated for NIST-10. Table 2 shows the comparison between the deflection of models M2-NIST-10 and M2-NIST-10-ATF at the location of the removed column in the various column loss cases. Progressive collapse, when it occurs, is designated as PC. Clearly, PC occurs in model M2-NIST-10 after interior gravity columns C-D5-1-N10 and C-E5-1-N10 are removed, but does not occur in any of the variant models M2-NIST-10-ATF, indicating that the added reinforcing bars prevent progressive collapse from happening. Adequate tie strength also reduced the overall deflection of the system significantly after loss of interior gravity column C-D4-1-N10 and exterior gravity column C-A5-1-N10. In neither of the cases, progressive collapse occurs to M2-NIST-10 but the displacement reaches 791 $\mathrm{mm}$ and $709 \mathrm{~mm}$, respectively. The reduction is $48 \%$ and $40 \%$, respectively. In all of the cases of removal of a gravity column which induces large deformation or progressive collapse in M2-NIST-10, the deformation given by M2-NIST-10-ATF is well below the maximum failure displacement, which is around $1300 \mathrm{~mm}$ as discussed in Alashker and El-Tawil [32]. Therefore, tie forces play a critical role in reducing system displacement when a gravity column is lost. However, when moment column(s) is (are) removed, the effect of the additional tie reinforcement is limited. The maximum difference between the displacements of M2-NIST-10 and M2-NIST-10-ATF is 11\% and the minimum difference is only $3 \%$ after the structure lost one or two moment columns simultaneously. The reason is that the deformation of the structure subjected to loss of a moment column is so small that membrane action in the slabs is not mobilized. Moreover, the contribution of the additional reinforcement to composite action is also limited. Therefore, it is not surprising that the differences between the responses of M2-NIST-10 and M2-NIST-10-ATF under such column loss scenarios are small. 
Table 2. Comparison between M2-NIST-10 and M2-NIST-10-ATF

\begin{tabular}{ccccc}
\hline Column lost & Column type & $\begin{array}{c}\text { M2-NIST-10 } \\
(\mathrm{mm})\end{array}$ & $\begin{array}{c}\text { M2- NIST-10-ATF } \\
(\mathrm{mm})\end{array}$ & Difference (\%) \\
\hline C-D4-1-N10 & Interior gravity & 791 & 536 & 48 \\
C-D5-1-N10 & Interior gravity & $\boldsymbol{P C}^{\mathbf{1}}$ & 576 & NA \\
C-D6-1-N10 & Exterior moment & 82 & 74 & 11 \\
C-E5-1-N10 & Interior gravity & $\boldsymbol{P C}^{1}$ & 535 & NA \\
C-E6-1-N10 & Exterior moment & 29 & 28 & 4 \\
C-D6-1-N10/ & Exterior moment & $457 / 348$ & $417 / 317$ & $10 / 10$ \\
C-E6-1-N10 & & 709 & 506 & 40 \\
C-A5-1-N10 & Exterior gravity & 47 & 43 & 9 \\
C-F6-1-N10 & Corner moment & 69 & 66 & 5 \\
C-E4-1-N10 & Interior moment & & & 4 \\
\hline
\end{tabular}

$\boldsymbol{P C}^{\mathbf{1}}$ : Progressive collapse

\subsection{SAC Buildings}

The same comparisons are made between models M2-SAC-X and M2-SAC-X-ATF and numerous column loss cases are conducted, including 12 column loss cases for SAC-3, 9 column loss cases for SAC-9, and 8 column loss cases for SAC-20. The simulation results are listed in Table 3 to Table 5. From Table 3 to Table 5 and similar trend was observed with those observed in NIST-10. The SAC buildings without adequate tie forces collapse after loss of a gravity column except loss of column C-C4-1-S20, in which the lost column has a small tributary area and the permanent deformation is $608 \mathrm{~mm}$. Progressive collapse is prevented in all of the corresponding column loss cases conducted using model M2-SAC-X-ATF. The deformation obtained by M2-SAC-20-ATF after loss of column C-C4-1-S20 is $436 \mathrm{~mm}$, which is $28 \%$ smaller than the one given by model M2-SAC-20. These results suggest that the additional reinforcement used for required tie forces contribute significantly to the system's collapse resistance after loss of a gravity column.

Table 3 demonstrates that the overall deflection of model M2-SAC-3 after loss of a moment column is much higher comparing with the other three buildings. In particular, the deformation of model M2-SAC-3 reaches as high as $648 \mathrm{~mm}$ after loss of the exterior moment column C-C5-1 of building $\mathrm{SAC}-3$. This is because this particular column has only one moment connection on one side of the column. The shear connections connected to the other sides of the removed column fail immediately after loss of the column in both models M2-SAC-3 and M2-SAC-3-ATF. However, the deformation is reduced by $24 \%$ in model M2-SAC-3-ATF. The failure mechanisms of M2-SAC-3 and M2-SAC-3-ATF are shown in Figure 4. The reduction in the permanent deformation induced by the additional reinforcing bars ranges from $9 \%$ to $25 \%$ in the other moment column loss cases. For buildings SAC-9 and SAC-20, deformations given by both M2-SAC-X and M2-SAC-X-ATF after loss of moment columns are small. The reduction in deformation attributed to the reinforcing bars ranges from $3 \%$ and $12 \%$. 
Table 3. Comparison between M2-SAC-3 and M2-SAC-3-ATF

\begin{tabular}{ccccc}
\hline Column lost & Column type & $\begin{array}{c}\text { M2-SAC-3 } \\
(\mathrm{mm})\end{array}$ & $\begin{array}{c}\text { M2-SAC-3-ATF } \\
(\mathrm{mm})\end{array}$ & Difference (\%) \\
\hline C-A3-1-S3 & Exterior moment & 113 & 97 & 14 \\
C-A4-1-S3 & Exterior moment & 112 & 102 & 9 \\
C-A5-1-S3 & Corner moment & 254 & 191 & 25 \\
C-B3-1-S3 & Interior gravity & $\boldsymbol{P C}^{\mathbf{1}}$ & 939 & N/A \\
C-B4-1-S3 & Interior gravity & $\boldsymbol{P C}^{\mathbf{1}}$ & 900 & N/A \\
C-B5-1-S3 & Exterior gravity & $\boldsymbol{P C}^{\mathbf{1}}$ & 1191 & N/A \\
C-C3-1-S3 & Interior gravity & $\boldsymbol{P C}^{\mathbf{1}}$ & 886 & N/A \\
C-C4-1-S3 & Interior gravity & $\boldsymbol{P C}^{\mathbf{1}}$ & 848 & N/A \\
C-C5-1-S3 & Exterior moment & 648 & 495 & 24 \\
C-D3-1-S3 & Interior gravity & $\boldsymbol{P C}^{\mathbf{1}}$ & 885 & N/A \\
C-D4-1-S3 & Interior gravity & $\boldsymbol{P C}^{\mathbf{1}}$ & 828 & N/A \\
C-D5-1-S3 & Exterior moment & 121 & 95 & 21 \\
\hline
\end{tabular}

$\boldsymbol{P C}^{1}$ : Progressive collapse

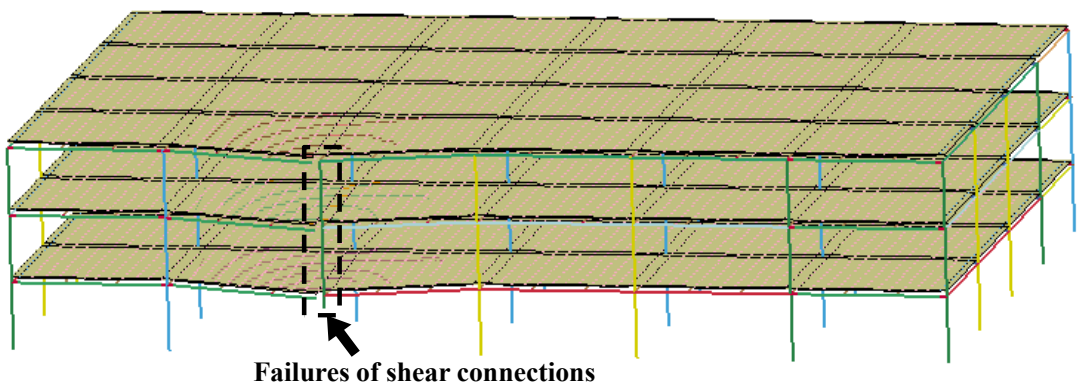

(a) Failure model of M2-SAC-3-ATF

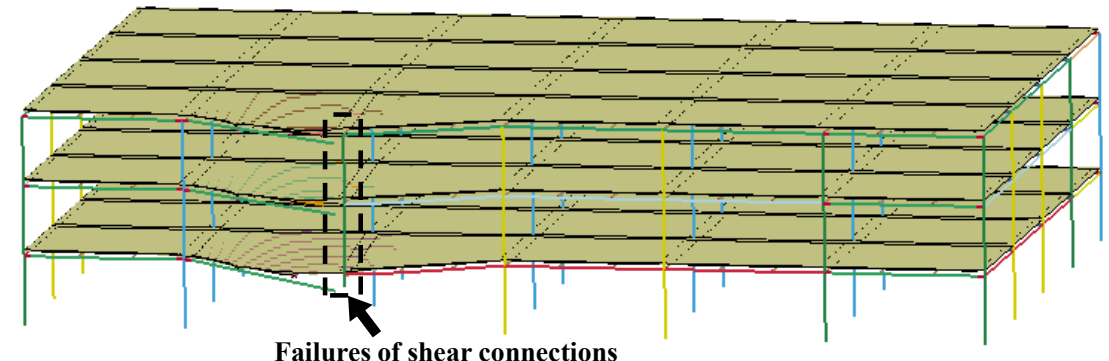

(b) Failure model of M2-SAC-3

Figure 4. Comparison between failure modes M2-SAC-3 vs. M2-SAC-3-ATF: loss of column C-C5-1 
Table 4. Comparison between M2-SAC-9 and M2-SAC-9-ATF

\begin{tabular}{ccccc}
\hline Column lost & Column type & $\begin{array}{c}\text { M2-SAC -3 } \\
(\mathrm{mm})\end{array}$ & $\begin{array}{c}\text { M2-SAC-3-ATF } \\
(\mathrm{mm})\end{array}$ & Difference (\%) \\
\hline C-A4-1-S9 & Exterior moment & 29 & 27 & 7 \\
C-A5-1-S9 & Exterior moment & 30 & 28 & 7 \\
C-A6-1-S9 & Corner moment & 34 & 30 & 12 \\
C-B4-1-S9 & Interior gravity & $\boldsymbol{P C}^{\mathbf{1}}$ & 792 & N/A \\
C-B5-1-S9 & Interior gravity & $\boldsymbol{P C}^{\mathbf{1}}$ & 829 & N/A \\
C-B6-1-S9 & Exterior moment & 43 & 40 & 7 \\
C-C4-1-S9 & Interior gravity & $\boldsymbol{P C}^{\mathbf{1}}$ & 864 & N/A \\
C-C5-1-S9 & Interior gravity & $\boldsymbol{P C}^{\mathbf{1}}$ & 864 & N/A \\
C-C6-1-S9 & Exterior moment & 29 & 28 & 3 \\
\hline
\end{tabular}

$\boldsymbol{P C}^{1}$ : Progressive collapse

In summary, from the comparisons described above, it can be concluded that the tie force method proposed in UFC 4-023-03 (DoD [2]) can effectively protects the steel special moment frame buildings against progressive collapse under column loss scenarios and is able to reduce the overall deflections of the structural systems significantly under large deformation conditions when catenary action developed by the ties plays a key role in resisting progressive collapse.

\section{CALCULATION OF DYNAMIC INCREASE FACTOR}

There are three procedures which are commonly used for the analysis of progressive building collapse: linear static, nonlinear static and nonlinear dynamic under the scheme of APM. Among these three procedures, linear static procedure is rarely used in the research of progressive building collapse because of the inaccuracy. Nonlinear dynamic analysis in conjunction with APM is widely viewed as the most comprehensive method. However, it requires extensive computational resources and is time consuming to perform such analyses. Thus, nonlinear static procedure might be a reasonable compromise between accuracy and computational time. One of the problem associated with nonlinear static procedure is that static procedures do not capture the dynamic nature of the column removal problem. One convenient way to do so is to apply a Dynamic Increase Factor (DIF) to the results of static models to account for the response magnification associated with dynamic behavior. The DIF can be defined as the ratio of the loads applied statically and dynamically when the structure is subjected to the same deformation demand. The DIF is used to amplify the gravity loads which are applied to the structure when nonlinear static procedure is implemented in order to estimate the dynamic peak displacement. In the latest version of UFC 4-023-03 (DoD [2]), the DIF for steel frame structures is specified as follows:

$$
\Omega_{N}=1.08+\frac{0.76}{\theta_{p r a} / \theta_{y}+0.83}
$$


Where $\theta_{\text {pra }}$ is the plastic rotation angle given in Table 5-6 of ASCE 41-06 (ASCE [29]) for the collapse prevention condition; and $\theta_{\mathrm{y}}$ is the yield rotation according to Equation 5-1 in ASCE 41-06 (ASCE [20]).

Table 5. Comparison between M2-SAC-20 and M2-SAC-20-ATF

\begin{tabular}{ccccc}
\hline Column lost & Column type & $\begin{array}{c}\text { M2-SAC-20 } \\
(\mathrm{mm})\end{array}$ & $\begin{array}{c}\text { M2-SAC-20-ATF } \\
(\mathrm{mm})\end{array}$ & Difference (\%) \\
\hline C-A4-1-S20 & Exterior moment & 19 & 18 & 5 \\
C-A5-1-S20 & Exterior moment & 20 & 19 & 5 \\
C-A6-1-S20 & Exterior moment & 24 & 22 & 8 \\
C-A7-1-S20 & Corner moment & 26 & 24 & 8 \\
C-B7-1-S20 & Exterior moment & 11 & 10 & 9 \\
C-C4-1-S20 & Interior gravity & 608 & 436 & 28 \\
C-C5-1-S20 & Interior gravity & $\mathbf{P C}$ & 649 & N/A \\
C-C7-1-S20 & Exterior moment & 18 & 17 & 6 \\
\hline
\end{tabular}

$\boldsymbol{P C}^{\mathbf{1}}$ : Progressive collapse

Table 6. Comparison between DIF ${ }_{\text {DoD, }}$ DIF $_{N S}$, and DIF real: NIST-10 Building

\begin{tabular}{cccc}
\hline Column lost & DIF & DIF $_{\text {NS }}$ & DIF $_{\text {real }}$ \\
\hline C-D6-1-N10 & 1.32 & 1.40 & 1.49 \\
C-E6-1-N10 & 1.32 & 1.96 & 1.46 \\
C-F6-1-N10 & 1.32 & 1.85 & 1.45 \\
C-D6-5-N10 & 1.32 & 1.25 & 1.50 \\
C-E6-5-N10 & 1.32 & 1.97 & 1.48 \\
C-F6-5-N10 & 1.32 & 1.78 & 1.48 \\
\hline
\end{tabular}

Eq. 4 was obtained from curve fitting and thus lacks a theoretical basis. Furthermore, the three-dimensional models used to formulate the equation (McKay et al. [33]) did not include the slabs, which were shown in Li and El-Tawil [29] to contribute significantly to collapse response and should be considered as primary components according to UFC 4-023-03 (DoD [2]).

A series of cases studies in the context of APM are conducted in order to verify whether Eq. 4 is able to produce a reasonable value of DIF. The M2-X -ATF model is used in these simulations since UFC 4-023-03 (DoD [2]) require that "for elements with inadequate horizontal tie force capacity, the Alternate Path method cannot be used". The following steps have to be performed to assess the DIF according to the procedures proposed in McKay et al. [33] and UFC 4-023-03 (DoD [2]):

a. Nonlinear dynamic analysis is performed using the design gravity loads. The APM is employed and the peak dynamic displacement of the removed column is recorded. 
b. Using the same model in Step 1, a nonlinear static analysis is performed. Increased the gravity loads with a trial DIF are applied in the effective area of the removed column.

c. Repeat step 2 until the deformation matches with the one computed in step 1.

The comparisons between the dynamic increase factors calculated according to Eq. 4 (DIFDoD) and the DIFs obtained based on the simulation results of model M2-NIST-10-ATF (DIF real) and M2-NIST-10-NS (DIFNS) following the steps outlined above under various column loss scenarios are shown in Table 6. Model M2-NIST-10-NS is identical to M2-NIST-10 except the floor slabs are removed. Only moment column loss cases are considered because collapse will occur if a gravity column is removed from M2-NIST-10-NS. From Table 6, large differences between DIF ${ }_{\text {DoD }}$ and $\mathrm{DIF}_{\text {real }}$ can be seen, indicating that Eq. 4 fails to produce reasonable DIFs. The differences between $\mathrm{DIF}_{\mathrm{DoD}}$ and $\mathrm{DIF}_{\mathrm{NS}}$ are even larger although the models employed in UFC 4-023-03 (DoD [2]) to formulate the equation did not considered the effects of the slab system, either. For example, the differences between $\mathrm{DIF}_{\mathrm{NS}}$ and $\mathrm{DIF}_{\mathrm{Doe}}$ are $51 \%, 42 \%$ and $52 \%$ when moment columns C-E6-1-N10, C-F6-1-N10, and C-E6-5-N10 are removed, respectively. The comparisons between $\mathrm{DIF}_{\mathrm{DoD}}$ and DIFNS also reveal that the presence of the slabs is not the reason for such inaccuracy. Therefore, it can be concluded that as an empirical equation obtained from curve fitting and without any theoretical basis, Eq. 4 specified in UFC 4-023-03 (DoD [2]) for calculating DIF is problematic.

Another interesting observation from Table 6 is that the slabs have a significant impact on the values of DIFs based on the comparison between DIFNS and DIF real. It can be seen that the DIF real

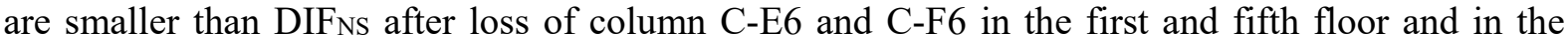

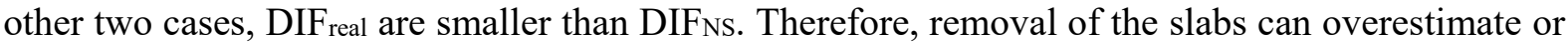
underestimate the value of DIF thus the slab floor system has to be considered if accurate DIF is aimed to be obtained.

Table 7 to Table 10 show the comparisons between DIF $_{\text {real }}$ and DIF ${ }_{\text {DoD }}$ for the prototype buildings in various column loss cases. In these tables, a positive difference means UFC 4-023-03 (DoD [2]) underestimate the values of DIFs, and a negative difference means UFC 4-023-03 (DoD [2]) overestimate the values of DIFs. From these tables, a common trend for the four buildings is

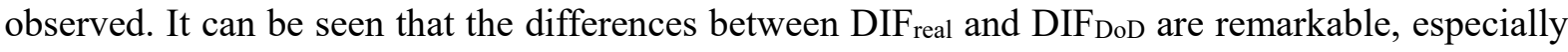
in the column loss cases when gravity columns are removed. For NIST-10 building, the difference ranges from $16 \%$ to $30 \%$ when a gravity column is removed. The deviations are around $40 \%$ for SAC-3 and SAC-9 and 30\% for SAC-20 under single gravity column loss scenarios. Eq. 4 can estimate the DIFs reasonably after loss of moment columns, which induce relatively small deformations. Table 6 to Table 9 demonstrate that the differences between DIF real and DIF DoD $_{\text {are }}$ under $15 \%$ when the lost columns are in the moment resisting system. It also should be noted that the UFC method underestimated the DIF in most of the column loss conducted herein. Therefore, it can be concluded that the DIF specified in UFC 4-023-03 (DoD [2]) is inaccurate and unconservative. 
Table 7. Comparison between DIF real $_{\text {and DIF }}$ DoD: NIST-10 Building

\begin{tabular}{lccc}
\hline Column lost & DIF & DIF $_{\text {real }}$ & Difference \\
\hline C-A5-1-N10 & 1.32 & 1.72 & $30 \%$ \\
C-D4-1-N10 & 1.32 & 1.70 & $29 \%$ \\
C-D6-1-N10 & 1.32 & 1.49 & $13 \%$ \\
C-E4-1-N10 & 1.32 & 1.30 & $-2 \%$ \\
C-E5-1-N10 & 1.32 & 1.53 & $16 \%$ \\
C-E6-1-N10 & 1.32 & 1.46 & $11 \%$ \\
C-F6-1-N10 & 1.32 & 1.45 & $10 \%$ \\
C-A5-5-N10 & 1.32 & 1.64 & $24 \%$ \\
C-D4-5-N10 & 1.32 & 1.71 & $30 \%$ \\
C-D6-5-N10 & 1.32 & 1.50 & $14 \%$ \\
C-E4-5-N10 & 1.32 & 1.30 & $-2 \%$ \\
C-E5-5-N10 & 1.32 & 1.53 & $16 \%$ \\
C-E6-5-N10 & 1.32 & 1.48 & $12 \%$ \\
C-F6-5-N10 & 1.32 & 1.48 & $12 \%$ \\
\hline
\end{tabular}

Table 8. Comparison between DIFreal and DIFDoD: SAC-3 building

\begin{tabular}{cccc}
\hline Column lost & DIF $_{\text {DoD }}$ & DIF $_{\text {real }}$ & Difference (\%) \\
\hline C-A3-1-S3 & 1.38 & 1.48 & 7 \\
C-A4-1-S3 & 1.38 & 1.49 & 8 \\
C-A5-1-S3 & 1.38 & 1.45 & 5 \\
C-B3-1-S3 & 1.28 & 1.85 & 45 \\
C-B4-1-S3 & 1.28 & 1.82 & 42 \\
C-B5-1-S3 & 1.28 & 1.82 & 42 \\
C-C3-1-S3 & 1.28 & 1.85 & 48 \\
C-C4-1-S3 & 1.28 & 1.84 & 44 \\
C-C5-1-S3 & 1.38 & 1.39 & 1 \\
C-D3-1-S3 & 1.28 & 1.87 & 46 \\
C-D4-1-S3 & 1.28 & 1.85 & 45 \\
C-D5-1-S3 & 1.38 & 1.52 & 10 \\
\hline
\end{tabular}


Table 9. Comparison between DIF real $_{\text {and DIF }}$ DoD: SAC-9 Building

\begin{tabular}{cccc}
\hline Column lost & DIF ${ }_{\text {DoD }}$ & DIF $_{\text {real }}$ & Difference (\%) \\
\hline C-A4-1-S9 & 1.33 & 1.50 & 13 \\
C-A5-1-S9 & 1.33 & 1.52 & 14 \\
C-A6-1-S9 & 1.33 & 1.46 & 10 \\
C-B4-1-S9 & 1.28 & 1.83 & 43 \\
C-B5-1-S9 & 1.28 & 1.79 & 40 \\
C-B6-1-S9 & 1.33 & 1.46 & 10 \\
C-C4-1-S9 & 1.28 & 1.80 & 41 \\
C-C5-1-S9 & 1.28 & 1.79 & 40 \\
C-C6-1-S9 & 1.33 & 1.41 & 8 \\
\hline
\end{tabular}

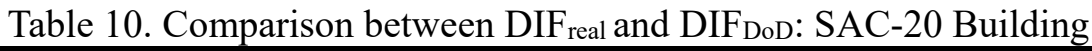

\begin{tabular}{cccc}
\hline Column lost & DIF $_{\text {DoD }}$ & DIF $_{\text {real }}$ & Difference (\%) \\
\hline C-A4-1-S20 & 1.30 & 1.42 & 9 \\
C-A5-1-S20 & 1.30 & 1.38 & 6 \\
C-A6-1-S20 & 1.30 & 1.40 & 8 \\
C-A7-1-S20 & 1.30 & 1.27 & -2 \\
C-B7-1-S20 & 1.30 & 1.34 & 3 \\
C-C4-1-S20 & 1.30 & 1.66 & 28 \\
C-C5-1-S20 & 1.30 & 1.74 & 34 \\
C-C7-1-S20 & 1.30 & 1.28 & -2 \\
\hline
\end{tabular}

On the other hand, it also reveals another two problems associated with Eq. 4: 1) $\theta_{p r a} / \theta_{y}$ is member dependent and not system dependent, and 2) certain members may be predominate in the DIF calculations. In other words, the members or connections with the smallest value of $\theta_{p r a} / \theta_{y}$ may associate with the same member section and structural layouts for the different column loss cases, and thus lead to the same DIF values. For example, an all of the column loss cases of NIST-10 building, the control member is the gravity beam in East-West direction. Such beams are considered primary members and not neglected in this study because they are not considered to be pinned at both ends and the flexural strength of the shear connection is not neglected and the value of $\theta_{\text {pra }} / \theta_{y}$ for the member is the smallest among the primary structural component is the effective area of the removed column. Table 6 to Table 9 show that the actual value of DIF do depend on the type of the removed column. 


\section{ENERGY-BASED APPROACH FOR ASSESSING PEAK DYNAMIC DISPLACEMENT}

The purpose of using DIF is to assess the peak dynamic displacement of a system under column loss scenarios through nonlinear static procedure. Since it has already been shown that the DIF specified in UFC 4-023-03 (DoD [2]) is not accurate nor conservative. It was discussed that the approach suffers from several critical drawbacks and that it is based on empirical data. To resolve this problem, a new approach for assessing PDD is proposed herein.

\subsection{Energy-based Approach for Assessment of Peak Dynamic Displacement}

To illustrate a general idea of the approach, a 4 slab-panel system with the mid-column removed as shown in Figure 5 is considered herein. It is assumed that the uniformly distributed load (UDL) that is applied to the system is $w 0$. According to Izzundin et al. [34], if the column is removed suddenly, the external work done by the UDL when the PDD $\Delta_{\mathrm{D}}$ is reached is:

$$
W_{e x t}=\alpha w_{0} \Delta_{D}
$$

where $\alpha$ is a work-related factor that depends on the gravity load distribution and when $w$ is identical everywhere, it is a constant which depends on the deformed shape of the floor system.

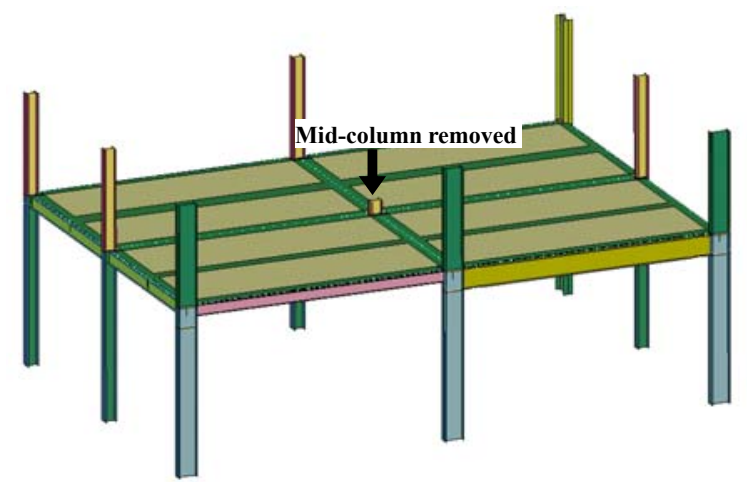

Figure 5. 4 slab-panel System with Mid-column Removed

Assume that the load-deflection response $w(\Delta)$ of the system obtained from a static push-down analysis is as shown in Figure 6(a). When the PDD of the system is reached, the internal energy stored in the system can be expressed as:

$W_{i n t}=\int_{0}^{\Delta_{D}} \alpha w(\Delta) d \Delta$

When the PDD is achieved, the kinematic energy stored in the system is zero. According to the law of energy conservation, an equality can be established, which is $W_{\text {ext }}=W_{\text {int }}$. It is reasonable to assume that the deformation modes of the system under dynamic and static loading conditions are the same. Therefore, the constant $\alpha$ can be eliminated. Thus,

$$
w_{0} \Delta_{D}=\int_{0}^{\Delta_{D}} w(\Delta) d \Delta
$$


The PDD of the system can be expressed as:

$\Delta_{D}=\frac{\int_{0}^{\Delta_{D}} w(\Delta) d \Delta}{w_{0}}$

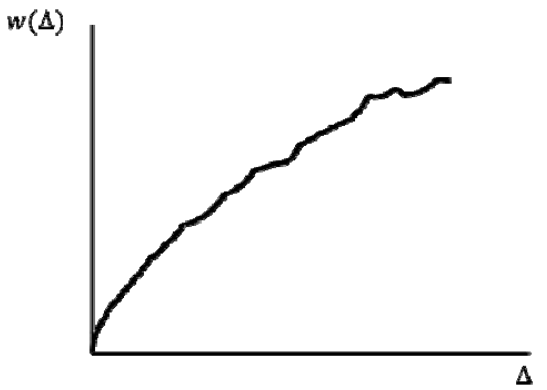

(a) Load-deflection curve obtained by static push-down

Figure 6. Load-deflection Curve for the 4-slab Panel System

The relationship in Figure 6(a) can be approximated as a bi-linear relationship as shown in Figure 6(b). The assumption is reasonable since the force-displacement relationships obtained from a number of static push-down experimental tests conducted recently to test the robustness of bolted connections, semi-rigid connections and rigid connections under column loss scenarios (Li et al. [35], Guo et al. [36], Yang and Tan [37], Guo et al. [38], Weigland and Berman [39], and Wang et al. [40]) could be simplified as bi-linear without losing too much critical information. As shown in Figure 6(b), the bi-linear relationship can be defined by $w 1, w 2$ and their corresponding displacement $\Delta_{l}$ and $\Delta_{2} w_{1}$ is the UDL when the system reaches is elastic stage since the initial stage of the force-displacement relationship in a static push-down test should be linear as shown in the progressive collapse tests mentioned above. On the other hand, $w_{1}$ could be calculated based on the size of the cross section of the structural components, which should be larger than the factored loads which should be carried by the system. $w_{2}$ is greater than $w_{2}$ and $w_{2}=\beta w_{1}$, in which $\beta>1$. For simplicity, the factored design gravity load $w_{0}=1.2 D+0.5 L$ required by UFC 4-023-03(DoD [2]) is used instead of $w_{1}$ and thus $w_{2}=\beta w_{0}$. This assumption is reasonable because the quantitative difference between $w_{0}$ and $w_{1}$ should be within a reasonable range according to the Load and Resistance Factor Design method. The displacements corresponding to $w_{0}$ and $\beta w_{0}$ are $\Delta_{01}$ and $\Delta_{02}$, respectively. $\Delta_{\mathrm{D}}$ is deemed to be larger than $\Delta_{01}$, which is obtained from the nonlinear static analysis without the application of the DIF, but not necessarily smaller than $\Delta_{02}$. Thus, the approximated bi-linear force-displacement relationship $w(\Delta)$ of the structural system can be expressed as:

$w(\Delta)=\left\{\begin{array}{cl}\frac{w_{0}}{\Delta_{01}} \Delta, & \Delta \leq \Delta_{01} \\ \frac{w_{0}}{\Delta_{02}-\Delta_{01}}\left[(\beta-1) \Delta+\Delta_{02}-\beta \Delta_{01}\right], & \Delta>\Delta_{01}\end{array}\right.$ 


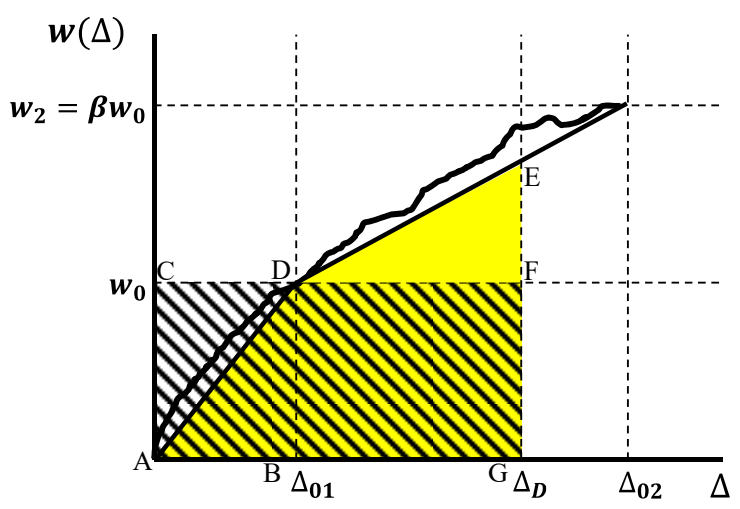

Figure 7. Energy-based Approach for Assessing Peak Dynamic Displacement $\Delta_{\mathrm{D}}$

An energy-based approach for assessment of PDD can be established based on this simplification. As shown in Figure 7, the hatched area represents the left-hand side of Eq. 7 and the shaded area represents the right-hand side of Eq. 7. To equate the hatched area to the shaded area, the area of the triangle ACD has to be equal to the area of the triangle DEF since triangle ABD and rectangular BDFG are shared by the hatched area and the shaded area. Thus,

$$
\frac{1}{2} w_{0} \Delta_{01}=\frac{1}{2}\left[w\left(\Delta_{D}\right)-w_{0}\right]\left(\Delta_{D}-\Delta_{01}\right)
$$

By substituting Eq. 9 into Eq. 10,

$$
\frac{1}{2} w_{0} \Delta_{01}=\frac{1}{2}\left\{\frac{w_{0}}{\Delta_{02}-\Delta_{01}}\left[(\beta-1) \Delta_{D}+\Delta_{02}-\beta \Delta_{01}\right]-w_{0}\right\}\left(\Delta_{D}-\Delta_{01}\right)
$$

By solving this equation, the PDD can be obtained:

$$
\Delta_{D}=\Delta_{01}+\sqrt{\frac{\Delta_{01}\left(\Delta_{02}-\Delta_{01}\right)}{\beta-1}}
$$

Thus, the PDD can be estimated through a simple equation as long as $\Delta_{01}$ and $\Delta_{02}$ are acquired. The implementation of the proposed method requires the following steps:

i. Conduct a nonlinear static analysis using APM with the application of the gravity load $w 0=$ $1.2 \mathrm{D}+0.5 \mathrm{~L}$ and record the corresponding displacement $\Delta 01$;

ii. Conduct another nonlinear static analysis using APM with the application of the gravity load $\beta w_{0}$ and record the corresponding displacement $\Delta_{02}$;

iii. Use Eq. 12 to calculate the PDD of the system.

\subsection{Verification of the Proposed Approach}

In order to verify the accuracy of the proposed approach, a large number of case studies are conducted using the numerical models M2-X-ATF for all of the four prototype buildings. Nonlinear dynamic analyses are firstly performed to obtain the PDD for comparison purposes. Then nonlinear static analyses are conducted on the basis of the proposed approach and the method for the calculation of the DIF specified in UFC 4-023-03 (DoD [2]) under the same column loss scenarios. Table 11 to Table 14 show the comparisons between the normalized peak displacements obtained 
by the two methods. "PDD" listed in these tables is nonlinear dynamic PDD and is used as reference in this section. Normalized peak displacement is defined as the ratio between the estimated PDD on the basis of the proposed method or UFC 4-023-03 (DoD [2]) (UFC method) to the PDD obtained from the nonlinear dynamic analyses. Based on a trial and error process, the value of $\beta$ used in all of the case studies is set to 1.3. Considering the values of the DIFs are between 1.30 to 1.70 in most of the cases in this study as shown in Table 6 to Table 9, this number is reasonable.

Table 11. Comparison between the Normalized Peak Dynamic Displacements (NPDD) Obtained from the Proposed Method and the UFC Method: NIST-10 Building

\begin{tabular}{cccc}
\hline Column lost & PDD $^{1}(\mathrm{~mm})$ & $\begin{array}{c}\text { NPDD: Proposed } \\
\text { method }\end{array}$ & $\begin{array}{c}\text { NPDD: UFC } \\
\text { method }\end{array}$ \\
\hline C-A5-1-N10 & 644 & 1.02 & 0.69 \\
C-D4-1-N10 & 660 & 1.05 & 0.69 \\
C-D6-1-N10 & 114 & 1.16 & 0.76 \\
C-E4-1-N10 & 101 & 1.33 & 0.90 \\
C-E5-1-N10 & 664 & 1.07 & 0.71 \\
C-E6-1-N10 & 43 & 1.27 & 0.84 \\
C-F6-1-N10 & 59 & 1.24 & 0.83 \\
C-A5-5-N10 & 652 & 1.05 & 0.70 \\
C-D4-5-N10 & 685 & 1.03 & 0.67 \\
C-D6-5-N10 & 149 & 1.09 & 0.72 \\
C-E4-5-N10 & 167 & 1.21 & 0.86 \\
C-E5-5-N10 & 684 & 1.07 & 0.70 \\
C-E6-5-N10 & 53 & 1.28 & 0.84 \\
C-F6-5-N10 & 72 & 1.23 & 0.81 \\
\hline
\end{tabular}

${ }^{1}$ PDD: peak dynamic displacement obtained from nonlinear dynamic analyses

Table 12. Comparison between the Normalized Peak Dynamic Displacements (NPDD) Obtained from the Proposed Method and the UFC Method: SAC-3 Building

\begin{tabular}{cccc}
\hline Column lost & PDD $^{1}(\mathrm{~mm})$ & $\begin{array}{c}\text { NPDD: Proposed } \\
\text { method }\end{array}$ & $\begin{array}{c}\text { NPDD: UFC } \\
\text { method }\end{array}$ \\
\hline C-A3-1-S3 & 124 & 1.17 & 0.84 \\
C-A4-1-S3 & 129 & 1.14 & 0.84 \\
C-A5-1-S3 & 229 & 1.12 & 0.83 \\
C-B3-1-S3 & 989 & 1.11 & 0.70 \\
C-B4-1-S3 & 967 & 1.13 & 0.72
\end{tabular}




$\begin{array}{lccc}\text { C-B5-1-S3 } & 1308 & 1.07 & 0.68 \\ \text { C-C3-1-S3 } & 937 & 1.10 & 0.68 \\ \text { C-C4-1-S3 } & 912 & 1.10 & 0.73 \\ \text { C-C5-1-S3 } & 531 & 1.13 & 0.99 \\ \text { C-D3-1-S3 } & 933 & 1.04 & 0.67 \\ \text { C-D4-1-S3 } & 887 & 1.01 & 0.70 \\ \text { C-D5-1-S3 } & 123 & 1.04 & 0.84\end{array}$

${ }^{1}$ PDD: peak dynamic displacement obtained from nonlinear dynamic analyses

Table 13. Comparison between the Normalized Peak Dynamic Displacements (NPDD) Obtained from the Proposed Method and the UFC Method: SAC-9 Building

\begin{tabular}{cccc}
\hline Column lost & PDD $^{1}(\mathrm{~mm})$ & $\begin{array}{c}\text { NPDD: Proposed } \\
\text { method }\end{array}$ & $\begin{array}{c}\text { NPDD: UFC } \\
\text { method }\end{array}$ \\
\hline C-A4-1-S9 & 36 & 1.31 & 0.86 \\
C-A5-1-S9 & 39 & 1.28 & 0.87 \\
C-A6-1-S9 & 37 & 1.35 & 0.92 \\
C-B4-1-S9 & 858 & 1.06 & 0.69 \\
C-B5-1-S9 & 887 & 1.03 & 0.66 \\
C-B6-1-S9 & 53 & 1.34 & 0.91 \\
C-C4-1-S9 & 914 & 1.05 & 0.68 \\
C-C5-1-S9 & 916 & 1.07 & 0.69 \\
C-C6-1-S9 & 35 & 1.40 & 0.94 \\
\hline
\end{tabular}

${ }^{1}$ PDD: peak dynamic displacement obtained from nonlinear dynamic analyses

It can be seen from these tables that out of the 43 column loss cases considered herein, there are 42 cases in which the normalized peak displacements obtained on the basis of UFC method are smaller than 1.0, indicating that the UFC method underestimate the peak dynamic displacement in almost every single column loss case. The only exception is that the UFC method is overestimated the PDD by $3 \%$ when the SAC-20 building is subjected to loss of column C-A6-1-S20. The PDD of the NIST-10 building is underestimated by $30 \%$ by the UFC method when the building is subjected to loss of column C-D4-1-N10. In the case when column C-B5-1-S9 of SAC-9 building is removed, the PDD of the system is underestimated by 34\%. The UFC PDD of the SAC-20 building is $31 \%$ smaller than the PDD evaluated by the nonlinear dynamic analysis when the building is subjected to loss of column C-A7-1-S20. In summary, based on the simulation results, the UFC method underestimates the PDD of the structural systems by a range of $1 \%$ to $34 \%$, which means the vulnerability of the system is significantly underestimated and thus the UFC method is once again proved to be unsafe. 
Table 14. Comparison between the Normalized Peak Dynamic Displacements (NPDD) Obtained from the Proposed Method and the UFC Method: SAC-20 Building

\begin{tabular}{cccc}
\hline Column lost & PDD $^{1}(\mathrm{~mm})$ & $\begin{array}{c}\text { NPDD: Proposed } \\
\text { method }\end{array}$ & $\begin{array}{c}\text { NPDD: UFC } \\
\text { method }\end{array}$ \\
\hline C-A4-1-S20 & 20 & 1.40 & 0.90 \\
C-A5-1-S20 & 20 & 1.40 & 0.95 \\
C-A6-1-S20 & 23 & 1.30 & 1.03 \\
C-A7-1-S20 & 26 & 1.32 & 0.69 \\
C-B7-1-S20 & 11 & 1.45 & 0.97 \\
C-C4-1-S20 & 463 & 1.11 & 0.74 \\
C-C5-1-S20 & 688 & 1.15 & 0.75 \\
C-C7-1-S20 & 19 & 1.42 & 0.99 \\
\hline
\end{tabular}

${ }^{1}$ PDD: peak dynamic displacement obtained from nonlinear dynamic analyses

In contrast, the proposed approach shows reasonable accuracy and is fairly conservative. The normalized PDDs estimated by the proposed approach are between 1.01 and 1.45 according to Table 11 to Table 14. In the cases when the PDD is smaller than $100 \mathrm{~mm}$, the proposed approach typically overestimates the PDD by $20 \%$ to $40 \%$, such as the cases of loss of columns C-E6-1-N10, C-F6-1-N10, C-E6-5-N10, and C-F6-5-N10 of the NIST-10 building, loss of columns column C-A4-1-S9, C-A5-1-S9, C-A6-1-S9, C-B6-1-S9, and C-C6-1-S9 of the SAC-9 building, loss of columns C-A4-1-S20, C-A5-1-S20, C-A6-1-S20, C-A7-1-S20, C-B7-1-S20, and C-C7-1-S20 of the SAC-20 buildings. These columns are all moment columns and loss of such columns is not critical for the system. However, for the column loss cases which result in large deformation (more than $100 \mathrm{~mm}$ ), the proposed method is very accurate and does not overestimate the PDD in a significant manner. For example, the normalized PDD calculated using the proposed approach in the case of removal of column C-A5-1 of the NIST-10 building is 1.02, which means the PDD estimated on the basis of the proposed approach matches the PDD obtained from the nonlinear dynamic analysis. In this case, the PDD is $644 \mathrm{~mm}$, as is shown in Table 11. Table 12 demonstrates that the normalized PDDs assessed on the basis of the proposed approach are all below 1.20 when SAC-3 building is subjected to various column loss scenarios. The PDD calculated according to the proposed approach is 3\% to 7\% larger than the corresponding nonlinear dynamic PDD under the loss of interior gravity columns of the SAC-9 building and the proposed method shows great accuracy in these cases. For the other column loss cases, the difference between the PDDs evaluated by implementing the proposed approach and the dynamic nonlinear procedure ranges from $10 \%$ and $17 \%$.

In summary, the proposed simplified energy-based method can estimate the PDD of the steel framed structures accurately and is reasonably conservative. It is also worthwhile to mention that the column loss cases considered herein incorporate different beam-column connection types, including the shear connection, WUF moment connections and RBS moment connections, and unlike the UFC method, the accuracy of the proposed method is not significantly influenced by the connection type. Therefore, the proposed method can be generally applied to the design of steel framed buildings with various connection types against progressive collapse. 


\subsection{Suitability of the Proposed Approach for Design Office Environment}

From the accuracy perspective, the PDD evaluated using the proposed approach has been shown to be more accurate comparing with the one calculated using the equation provided by UFC 4-023-03 (DoD [2]) in this study. On the other hand, as is mentioned earlier, the proposed approach is generally applicable to the steel framed structures with various types of beam-to-column connections, such as shear connections, WUF connections and RBS connections. Thirdly, the only calculation which needs to be done by hand in the proposed approach is the utilization of Eq. 12 . However, the UFC method requires more hand calculations to determine the values of $\theta_{\text {pra }}$ and $\theta_{\mathrm{y}}$ for the primary structural components.

Actually, the dynamic increase factor is no longer needed because by using the proposed method, the PDD can be calculated directly. Therefore, the proposed method could be a reasonable replacement of application of DIF for the purpose of estimating the peak dynamic displacement and thus evaluating the damage of the structure after loss of columns through nonlinear static analysis.

However, the proposed approach will be less accurate than the approach proposed by Izzundin et al. [34] because the proposed approach is an approximation of their method. However, from the computational perspective, the proposed approach outperforms the method proposed by Izzundin et al. [34]. In their method, a series of nonlinear static analyses are needed in order to obtain the static load-deflection curve of the system and a fairly complicated trial-and-error process is needed to obtained the PDD since it is an unknown and it serves as the upper limit of the integration.

On the other hand, the proposed method requires at most 2 nonlinear static simulations using the same model under different loading conditions. Although this is more effort than a single nonlinear static run, it is certainly less effort than running a full dynamic simulation, with all of its complications in modeling and data processing. Many commercial software packages can now run nonlinear static simulations, tracking the inelastic response of frame elements and even shell elements. Therefore, conducting the requisite static simulations is certainly within the capabilities of most design offices at present, rendering the method practical and suitable for routine application.

\section{CONCLUSIONS}

Two design requirements in the UFC 4-023-03 (DoD [2]) published by the US Department of Defense were evaluated, including Tie Force Method and criteria for the calculation of the Dynamic Increase Factor. To ensure that the analytical results are generally applicable, three-dimensional macro-based models for a pool of 4 buildings with different heights, structural layouts and seismic detailing were created. The modeling approach has been extensively validated in previous research (Alashker et al. [22] and Li and El-Tawil [29]). It was found the original design of these structures did not satisfy the Tie Force criteria and thus the buildings were redesigned to ensure adequate tie strength by adding reinforcing bars to the slabs of the structures. The responses of all four structures under column loss scenarios before and after the re-design were then compared to evaluate the efficacy of the TFM procedure in UFC 4-023-03 (DoD [2]). The DIFs of the prototype structures were obtained from the numerical simulations and compared with the DIFs calculated according to the method specified in UFC 4-023-03 (DoD [2]). It was found the UFC method were neither accurate nor conservative. To address this deficiency, a new, energy-based approach for assessing the peak dynamic displacement was proposed, in which the simulation results of two separate nonlinear static analyses were needed to compute the peak dynamic displacement. Extensive case studies were then conducted to assess the characteristics of the new method and the following conclusions are drawn: 
- The tie force method as implemented in UFC 4-023-03 (DoD [2]) can effectively protect the structures against progressive collapse under column loss scenarios. Ensuring adequate tie strength also reduces the overall deflection of the structural system significantly under large deformation conditions when catenary action plays a significant role in resisting progressive collapse although this effect is limited when the deformations are small.

- The method for the calculation of the dynamic increase factor for the steel framed structures specified in UFC 4-023-03 (DoD [2]) is neither accuracy nor conservative. The method is also unsafe because it may underestimate the peak dynamic displacement of a structure by $30 \%$ in some cases and thus significantly underestimate the vulnerability of the structure under column loss scenarios.

- The proposed energy-based approach for assessing the peak dynamic displacement of a structure after sudden column loss is reasonably accurate and conservative. It is also generally applicable to the steel framed structures with various types of beam-column connections. Although the proposed needs two separate nonlinear static analyses, its accuracy and simplicity make it attractive for use in a design office environment. Furthermore, considering the advantages of the proposed approach over the UFC method, it could be a reasonable replacement of application of DIF for the purpose of estimating the peak dynamic displacement and thus evaluating the damage of the structure after loss of columns through nonlinear static analysis.

\section{ACKNOWLEDGEMENT}

The presented work was supported by grants from the National Natural Science Foundation of China under Grant No. 51408152, Natural Science Foundation of Heilongjiang Province, China under Grant No. LC2016021, the Fundamental Research Funds for the Central Universities through grant HIT.NSRIF.2015098, China Postdoctoral Science Foundation through grant 2014M550194, and China Postdoctoral Science Foundation through grant 2015T80353. Any opinions, findings, conclusions, and recommendations expressed in this paper are those of the authors and do not necessarily reflect the views of the sponsors.

\section{REFERENCES}

[1] ASCE 7-10, "Minimum Design Loads for Buildings and other Structures", American Society of Civil Engineers, 2013.

[2] UFC 4-023-03, "Design of Buildings to Resist Progressive Collapse", Department of Defense, 2013.

[3] GSA, "Alternate Path Analysis \& Design guidelines for Progressive Collapse Resistance", U.S. General Service Administration, 2013.

[4] Moore, D.B., "The UK and European Regulations for Accidental Actions", Proceedings of Workshop on Prevention of Progressive Collapse, National Institute of Building Sciences, 2002.

[5] Abruzzo, J., Matta, A. and Panariello, G., "Study of Mitigation Strategies for Progressive Collapse of a Reinforced Concrete Commercial Building", Journal of Performance of Constructed Facilities, 2006, Vol. 20, No. 4, pp. 384-390.

[6] UFC 4-023-03, "Design of Buildings to Resist Progressive Collapse", Department of Defense, 2005.

[7] Li, Y., Lu, X., Guan, H. and Ye, L., "An Improved Tie Force Method for Progressive Collapse Resistance Design of Reinforced Concrete Frame Structures", Engineering Structures, 2011, Vol. 33, No. 10, pp. 2931-2942. 
[8] Tohidi,M., Yang, J. and Baniotopoulos, C., "Numerical Evaluation of Codified Design Methods for Progressive Collapse Resistance of Precast Concreate Cross Wall Structures", Engineering Structures, 2014, Vol. 76, pp. 177-186.

[9] Main, J.A., "Composite Floor Systems under Column Loss: Collapse Resistance and Tie Force Requirements", Journal of Structural Engineering, 2014, Vol. 140, No. 8, A4014003.

[10] GSA, "Progressive Collapse Analysis and Design Guidelines for New Federal Office Building and Major Modernization Project", U.S. General Service Administration, 2003.

[11] Ruth, P., Marchand, K.A. and Williamson, E.B., "Static Equivalency in Progressive Collapse Alternate Path Analysis: Reducing Conservatism while Retaining Structural Integrity", Journal of Performance of Constructed Facilities, 2006, Vol. 20, No. 4, pp. 349-364.

[12] Foley, C. M., Barnes, K. and Schneeman, C., "Quantifying and Enhancing Robustness in Steel Structures: Part 1 - Moment-Resisting Frames", Engineering Journal, American Institute of Steel Construction, 2008, $4^{\text {th }}$ Quarter, pp. 267-286.

[13] Khandelwal, K. and El-Tawil, S., "Pushdown Resistance as a Measure of Robustness in Progressive Collapse Analysis", Engineering Structures, 2011, Vol. 33, No. 9, pp. 2653-2661.

[14] Liu, M., "A New Dynamic Increase Factor for Nonlinear Static Alternate Path Analysis of Building Frames Against Progressive Collapse", Engineering Structures, 2013, Vol. 48, pp. 666-673.

[15] Yu, J., Rinder, T., Stolz, A., Tan, K.H. and Riedel, W., "Dynamic Progressive Collapse of an RC Assemblage Induced by Contact Detonation", Journal of Structural Engineering, 2014, Vol. 140, No. 6, A04014014.

[16] Ali, K., Mohsen, G. and Farshad, M., "Assessment of Dynamic Effect of Steel Frame due to Sudden Middle Column Loss", The Structural Design of Tall and Special Buildings, 2014, No. 23, No. 5, pp. 390-402.

[17] Liu, C., Tan, K.H. and Fung, T.C., "Investigations of Nonlinear Dynamic Performance of Top-and-Seat with Web Angle Connections subjected to Sudden Column Removal", Engineering Structures, 2015, Vol. 99, pp. 449-461.

[18] Liu, C., Tan, K.H. and Fung, T. C., "Dynamic Behavior of Web Cleat Connections subjected to Sudden Column Removal Scenario", Journal of Construction Steel Research, 2013, Vol. 86, pp. 92-106.

[19] Qian, K. and Li, B., "Quantification of Slab Influences on the Dynamic Performance of RC Frames against Progressive Collapse", Journal of Performance of Constructed Facilities, 2015, Vol. 29, No. 1, 04014029.

[20] Liang, X., Shen, Q. and Ghosh, S.K., "Assessing Ability of Seismic Structural System to Withstand Progressive Collapse: Seismic Design and Progressive Collapse Analysis of Steel Frame Buildings", Rep. Prepared for SK Ghosh and Associates, 2006.

[21] Khandelwal, K., El-Tawil, S., Kunnath, S.K. and Lew, H.S., "Macro-model Based Simulations of Progressive Collapse: Steel Frame Structures", Journal of Structural Engineering, 2008, Vol. 134, No. 7, pp. 1070-1078.

[22] Alashker, Y., Li, H. and El-Tawil, S., "Approximations in Progressive Modeling", Journal of Structural Engineering, 2011, Vol. 137, No. 9, pp. 914-924.

[23] FEMA 355C, "State of the Art Report on Systems Performance of Steel Moment Frames subjected to Earthquake Ground Shaking", Federal Emergency Management Agency, 2000.

[24] Foley, C. M., Martin, K. and Schneeman, C., "Robustness in Structural Steel Framing Systems", Final Report Submitted to the American Institute of Steel Construction, Inc., 2007.

[25] Hoffman, S.T., "Behavior and Performance of Steel Moment-Framed Buildings subjected to Dynamic Column Loss Scenarios", Master Thesis, University of Illinois at Urbana-Champaign, Urbana, Illinois, 2010.

[26] Hallquist, J., "LS-DYNA Keyword User's Manual”, Livermore Software Technology Corporation, Livermore, CA, Version 971, 2006. 
[27] Khandelwal, K. and El-Tawil, S., "Collapse Behavior of Steel Special Moment Resisting Frame Connections", Journal of Structural Engineering, 2007, Vol. 133, No. 5, pp. 646-655.

[28] Sadek, F., El-Tawil, S. and Lew, H.S., "Robustness of Composite Floor System with Shear Connections: Modeling, Simulation and Evaluation", Journal of Structural Engineering, 2008, Vol. 134, No. 11, pp. 1717-1725.

[29] Li, H. and El-Tawil, S., "Three-Dimensional Effects and Collapse Resistance Mechanisms in Steel Frame Buildings", Journal of Structural Engineering, 2014, Vol. 140, No. 8, A4014017

[30] ASCE 41-06., "Seismic Rehabilitation of Existing Buildings", American Society of Civil Engineers, 2007.

[31] Wight, J. and Macgregor, J., "Reinforced Concrete: Mechanics and Design (5 ${ }^{\text {th }}$ Edition)", Prentice Hall, 2008.

[32] Alashker, Y. and El-Tawil, S., "A Design-oriented Model for the Collapse Resistance of Composite Floors Subjected to Column Loss", Journal of Constructed Steel Research, 2011, Vol. 67, No. 1, pp. 84-92.

[33] McKay, A., Marchand, K. and Diaz, M., "Alternate Path Method in Progressive Collapse Analysis: Variation of Dynamic and Nonlinear Load Increase Factors", Practice Periodical on Structural Design and Construction, 2012, Vol. 17, No. 4, pp. 152-160.

[34] Izzuddin, B.A., Vlassis, A.G., Elghazouli, A.Y. and Nethercot, D.A., "Progressive Collapse of Multi-Storey Buildings Due to Sudden Column Loss - Part I: Simplified Assessment Framework", Engineering Structures, 2008, Vol. 30, No. 5, pp. 1308-1318.

[35] Li, L., Wang, W., Chen, Y. and Lu, Y., "Effect of Beam Web Bolt Arrangement on Catenary Behaviour of Moment Connections", Journal of Constructional Steel Research, 2015, Vol. 104, pp. 22-36.

[36] Guo L., Gao, S. and Fu, F., "Structural Performance of Semi-Rigid Composite Frame under Column Loss", Engineering Structures, 2015, Vol. 95, pp. 112-126.

[37] Yang, B. and Tan, K.H., "Experimental Tests of Different Types of Bolted Steel Beam-column Joints under a Central-column-removal Scenario", Engineering Structures, 2013, Vol. 54, pp. 112-130.

[38] Guo, L., Gao, S., Fu, F. and Wang, Y., "Experimental Study and Numerical Analysis of Progressive Collapse Resistance of Composite Frames", Journal of Constructional Steel Research, 2013, Vol. 89, pp. 236-251.

[39] Weigland, J. M. and Berman, J.W., "Integrity of Bolted Angle Connections Subjected to Simulated Column Removal", Journal of Structural Engineering, 2015, Vol. 142, No. 3, 04015165.

[40] Wang, W., Fang, C., Qin, X., Chen, Y. and Li, L., "Performance of Practical Beam-to-SHS Column Connections against Progressive Collapse”, Engineering Structures, 2016, Vol. 106, pp. 332-347. 